This item was submitted to Loughborough's Research Repository by the author.

Items in Figshare are protected by copyright, with all rights reserved, unless otherwise indicated.

\title{
Raising the bar for occupational health management in construction
}

PLEASE CITE THE PUBLISHED VERSION

https://doi.org/10.1680/jcien.19.00029

PUBLISHER

(C) ICE Publishing

VERSION

AM (Accepted Manuscript)

PUBLISHER STATEMENT

This paper was accepted for publication in the journal Proceedings of the Institution of Civil Engineers - Civil Engineering and the definitive published version is available at https://doi.org/10.1680/jcien.19.00029.

\section{LICENCE}

CC BY-NC-ND 4.0

\section{REPOSITORY RECORD}

Jones, Wendy, Alistair G.F. Gibb, Roger Haslam, and Jennie Armstrong. 2019. "Raising the Bar for Occupational Health Management in Construction”. figshare. https://hdl.handle.net/2134/38376. 


\section{Accepted manuscript doi: 10.1680/jcien.19.00029}

\section{Accepted manuscript}

As a service to our authors and readers, we are putting peer-reviewed accepted manuscripts (AM) online, in the Ahead of Print section of each journal web page, shortly after acceptance.

\section{Disclaimer}

The AM is yet to be copyedited and formatted in journal house style but can still be read and referenced by quoting its unique reference number, the digital object identifier (DOI). Once the AM has been typeset, an 'uncorrected proof' PDF will replace the 'accepted manuscript' PDF. These formatted articles may still be corrected by the authors. During the Production process, errors may be discovered which could affect the content, and all legal disclaimers that apply to the journal relate to these versions also.

\section{Version of record}

The final edited article will be published in PDF and HTML and will contain all author corrections and is considered the version of record. Authors wishing to reference an article published Ahead of Print should quote its DOI. When an issue becomes available, queuing Ahead of Print articles will move to that issue's Table of Contents. When the article is published in a journal issue, the full reference should be cited in addition to the DOI. 


\section{Accepted manuscript doi: 10.1680/jcien.19.00029}

Submitted: 20 May 2019

Published online in 'accepted manuscript' format: 02 July 2019

Manuscript title: Raising the bar for occupational health management in construction

Authors: Wendy Jones ${ }^{1 *}$, Alistair Gibb ${ }^{2}$, Roger Haslam³ ${ }^{3}$ Jennie Armstrong ${ }^{4}$

Affiliation: ${ }^{1}$ Researcher, School of Architecture, Building and Civil Engineering, Loughborough University, Loughborough, UK (Orcid:0000-0002-6523-9667); ${ }^{2}$ Professor, School of Architecture, Building and Civil Engineering, Loughborough University, Loughborough, UK; ${ }^{3}$ Professor, School of Design and Creative Arts, Loughborough University, Loughborough, UK; ${ }^{4}$ Head of Occupational Health, Safety and Wellbeing, Tideway, London, UK

*Corresponding author: Wendy Jones, Researcher, School of Architecture, Building and Civil Engineering, Loughborough University, Loughborough, UK

(Orcid:0000-0002-6523-9667)

E-mail: w.jones2@lboro.ac.uk 


\section{Accepted manuscript doi: 10.1680/jcien.19.00029}

\section{Abstract}

Construction-related ill-health, including respiratory conditions, hand-arm vibration syndrome, musculoskeletal disorders and stress related issues, has enormous personal and financial cost. Following research on major construction projects, a range of interventions are proposed in this paper, illustrated by examples from the Thames Tideway Tunnel project in London, UK. It is concluded that a consistent approach to occupational health management and health surveillance is needed across construction, with a commitment to better training and improved portability of occupational health data. Major projects are critical to raising health management standards but good practices need to be universally adopted in small- to medium-sized enterprises to achieve lasting improvement Keywords: health \& safety; management; safety \& hazards 


\section{Accepted manuscript doi: 10.1680/jcien.19.00029}

\section{Introduction}

An often-quoted statistic is that for each worker who dies from a construction-related accident in the UK, a further 100 die due to work-related ill-health. Many fatalities relate to past exposures, particularly to asbestos, and this figure is unlikely to fall for many years due to the long latency of the associated conditions. However, the construction workforce also continues to suffer substantial harm from current exposures to workplace hazards, which are proving resistant to improvement. For example, neither musculoskeletal disorders nor work-related mental health conditions have fallen substantially in prevalence since 2001 (HSE, 2018).

An Institution of Civil Engineers report in 2018 found that musculoskeletal disorders and mental ill-health together cost the sector's employers over $£ 800$ million each year (Gibb et al., 2018). The incidence of other conditions such as noise-induced hearing loss, dermatitis and asthma appears to have fallen in recent years, but the real number of cases is uncertain due to poor quality data and incomplete diagnoses (Stocks et al., 2015).

In work reported previously, Jones et al. used 237 interviews and 120 meeting observations on two major construction projects to examine the practical reasons why health risk is difficult to manage. The following factors were identified.

- 'Health' is typically a broader construct than 'safety' and often includes worker health external to the workplace; an over-focus on lifestyle can distract from the management of work-related hazards. 


\section{Accepted manuscript doi: 10.1680/jcien.19.00029}

- Health risks can be misjudged: the hazards and the diseases they cause are less visible than safety issues. They are also misjudged due to inadequate knowledge. Additionally, individual workers and organisations can become resigned to health risks, perceiving them as unavoidable (Figures 1 and 2).

- Occupational health is on the periphery for some safety practitioners, seen as the role of 'other' experts. It can be even further removed for managers.

- There is poor understanding regarding the requirements for health surveillance and other health checks.

- There are few perceived benefits for employers who pay for occupational health services and maintaining long term health records for a fragmented workforce is challenging.

This paper proposes ways in which individual companies and projects, and the sector more widely, could address these challenges (see Figure 3). Specific examples are given to illustrate how this might work in practice. These are largely drawn from the construction of the Thames Tideway Tunnel, a $£ 4$ billion project to construct a $25 \mathrm{~km}$ long, 7.5 m diameter sewer under the River Thames (see Fuller et al. (2017) for further details). This is not a paper about Tideway, rather the examples have been chosen to demonstrate the possible scope of interventions and to highlight the role that major projects can play in driving improvement in occupational health management throughout the sector. 


\section{Accepted manuscript doi: 10.1680/jcien.19.00029}

\section{Ownership and management of health}

In recent years, construction safety management has increasingly become incorporated into project management: occupational safety and health professionals have an advisory role, supporting the managers who carry the responsibility (e.g. Choudhry et al., 2008). This does not happen consistently with the management of health risks, nor do occupational safety and health professionals typically have the expertise to provide support. Possible reasons for this discrepancy include inadequate knowledge, reluctance of managers and occupational safety and health professionals to get involved in issues which are seen as 'personal', or distraction by involvement in more general health and wellbeing matters.

Figure 4 shows who might be involved in different aspects of workplace health. It includes the health of individual workers, and the broader wellbeing of the workforce as well as the management of health risks. It shows ownership of and accountability for health risk management as a core responsibility of line managers and supervisors, and that occupational safety and health professionals need to give equal attention to health risks and safety risks.

If managers are to accept ownership for health risks, they need to be supported by knowledgeable occupational safety and health practitioners, who are in turn supported by those with a particular expertise in health, such as occupational hygienists and occupational health nurses and advisers. The management of dust or vibration, for example, is no different from the management of confined spaces or fire 


\section{Accepted manuscript doi: 10.1680/jcien.19.00029}

safety, where an expert might be involved in planning but responsibility for implementation would be retained by line management.

Occupational hygienists are a relatively recent addition to the UK construction sector. A team was employed on the London 2012 Olympic Park construction and their involvement is mandated on the Tideway project, but only two or three large construction companies currently employ a hygienist in house. Increasing the availability of this expertise across the industry is important but will be challenging given a national shortfall of hygienists across all sectors in the UK (Harrison, 2014), with similar shortages of occupational health advisers, nurses and doctors (Raynal, 2015). This scarcity of specialists makes it even more important that managers and occupational safety and health professionals have a sound understanding of health risks.

As proposed in Figure 4, responsibility for wellbeing should be removed from the remit of occupational safety and health professionals. This would reduce the risk of such activities distracting from management of work-related health risks. Positioning wellbeing instead within human resources, for example, aligns it with other organisational policies which influence worker health. A recent paper on wellbeing published by the British Safety Council identifies health promotion activities as one small part of wellbeing, with a far greater influence coming from organisational practices such as leadership, manager skills and corporate social responsibility (British Safety Council, 2018). 


\section{Accepted manuscript doi: 10.1680/jcien.19.00029}

Organisations that do wish to become involved in health-promotion activities could engage a wide range of specialists including physiologists, psychologists, nutritionists and dentists.

\section{Improved education, training and information}

The research described in Jones et al. (submitted) found evidence of incomplete knowledge about health risks and how to manage them amongst some managers, occupational safety and health professionals and frontline workers. Increased education is needed at all levels.

Health is typically underplayed in most formal 'occupational safety and health training', for example the Nebosh Construction Certificate, the entry level qualification for an occupational safety and health practitioner in most small- to medium-sized projects or companies in the UK, includes only $5 \mathrm{~h}$ training to cover multiple health subjects (radiation, noise, vibration and stress). More traditional safety topics such as fire and working at height, however, are allocated 6-7 h each within the course structure. Shifting this balance would improve health skills and raise the profile. In the meantime, short courses are available through the UK Institution of Occupational Safety and Health and British Occupational Hygiene Society, suitable for those working at supervisor level or above, and could be a starting point for occupational safety and health professionals to develop their expertise.

Further training is also needed for frontline workers. Training needs to compensate for the low visibility of health hazards. For example, it can be difficult for workers to identify when noise is at a level which necessitates hearing protection or other 


\section{Accepted manuscript doi: 10.1680/jcien.19.00029}

intervention; and respirable dust is often invisible, leading workers to underestimate its significance. Additionally, the long latency of many health conditions means that damage may only be apparent after many years, so trainers need to find ways to help workers fully understand the impact.

By way of example, practical steps taken on the Tideway project to increase the knowledge of workers and managers include the following.

- Occupational hygienists are engaged by all the main contractors as a requirement of the works information. A key part of their role has been to improve the understanding of others about health risks and how to manage them.

- 'Essential standards' have been produced for the main hazards, these describe the hazard and the control measures typically required. They include examples of activities which commonly present low, medium and high risk and guidance on when specialist advice is required.

- Training sessions are provided for project managers, engineers, supervisors and others who contribute to risk assessments. These again focus on practical control measures.

- One-to-one coaching: to enhance training, hygienists spend time with individuals and provide specific support, for example to give feedback on risk assessment and method statements or to guide assessors through an inspection. 


\section{Accepted manuscript doi: 10.1680/jcien.19.00029}

- The Luskins interactive training tools have been used (Gibb et al., 2015) to simulate dermatitis, hand-arm vibration syndrome and back pain to enable workers to experience the longer-term impact of health conditions in the present (Figure 5).

- A bespoke card game has engaged workers by comparing the typical sound levels of household and work activities (Figure 6).

- Job-specific training and targeted toolbox talks have been delivered at the point of work, for example discussing the impact of wood dust for carpenters.

\section{Raising the visibility of health}

Good training can help workers and managers recognise health hazards and improve their understanding of control measures. Intervention from specialists to quantify hazards such as vibration and dust can also raise their visibility, making them more tangible and giving managers and workers 'permission' to address them. Personal dose meters and wearable technologies are even more engaging. They can also be used to demonstrate the effectiveness of control measures.

For health risks to be managed successfully, their prominence must also be raised at an organisational level. Safety metrics and key performance indicators are used in construction to measure occupational safety and health and generate information to share with senior decision makers. Inclusion of this information on dashboards for management teams positions safety alongside other priorities such as productivity, progress and cost, and has become the norm on most major projects. Health metrics also need to be included here to encourage senior managers to take ownership. 


\section{Accepted manuscript doi: 10.1680/jcien.19.00029}

For example, the health impact frequency rate was a measure developed during construction of London 2012 (Tyers and Hicks, 2012). An occupational hygienist visited each site weekly for $2 \mathrm{~h}$ and documented failures of health risk management, such as excessive dust or workers not wearing the recommended personal protective equipment. Sites were scored on their health risk management and comparisons could be drawn between different projects or sites.

For example, building on the London 2012 health impact frequency rate, the Tideway project has developed an occupational health index tool for measuring occupational health risk management. It is modelled on the Finnish TR system, a validated methodology for monitoring safety (Laitinen et al., 1999).

An assessor counts examples of good and poor practices on site, using a standard score sheet. The target is to record 100 practices, but this is not essential. Good practices might include, for example, use of water suppression or acoustic barriers. Poor practices will include uncontrolled risks and workers without adequate personal protective equipment. A score is calculated showing the good practices as a percentage of the overall.

Scores can be used to highlight health risks or work areas where intervention is needed. For example, the tool has identified poor use of hearing protection and an intervention was developed to tackle this. Assessment was originally conducted by the occupational hygienists to establish a baseline, but responsibility for inspection was subsequently handed over to site managers. Coaching and mentoring was provided by the hygienists to support this. 


\section{Accepted manuscript doi: 10.1680/jcien.19.00029}

A health and safety performance indicator has been set that measures the quality of the inspection, encouraging site teams to focus on trends and improvements rather than only on individual scores. Outcomes from the occupational health index score are included on senior management dashboards (see Figure 7).

There is an ongoing challenge in ensuring consistency between assessors.

Experience so far suggests that non-experts such as engineers and managers focus mostly on unmanaged risk and are less likely to notice good practice. An additional challenge is that site-based controls such as water suppression and personal protective equipment can be seen and measured. However, risks which have been designed out completely (the preferred option) are not visible and cannot be recognised or scored.

\section{Practice on large projects}

There is evidence that knowledge about good occupational safety and health practices in construction 'trickles down' from major projects and large companies to smaller organisations as individuals move between jobs and take their learning with them (Pinder et al., 2017).

For example, during construction of London 2012 it was assumed that high levels of engagement and good practice would result in improved knowledge and attitudes amongst construction managers, and improvement across the industry more widely (Tyers and Hicks, 2012). It was also recognised, however, that lasting impact would require clients to continue to set and enforce high standards to encourage contractors to adopt and embed these. 


\section{Accepted manuscript doi: 10.1680/jcien.19.00029}

Good procurement processes are essential and are an ideal opportunity for purchasers to give health 'equal billing' with safety at prequalification and pretender stages. Health standards must be clearly explained in tender documents so contractors can ensure they include sufficient resources in their bids to enable them to comply.

A process has been developed on Tideway to encourage subcontractors to improve their management of health. The project has developed a supply chain improvement tool that is similar to a maturity matrix. It provides a structured way for the main contractors' occupational safety and health professionals to support development of their supply chain. Figure 8 shows extracts from the tool. Key subcontractors are assessed against specific criteria under the headings 'Health strategy and leadership', 'Risk assessment and control', 'Fitness for work and health surveillance' and 'Wellbeing'. An output would be an action plan and a gold, silver, bronze rating for each element.

For example, a labour-only supplier on Tideway had worked on major projects and had a good safety record. Review using the tool identified that worker health was less well managed, health surveillance only occurred if it was specifically required for a particular project and provided by the principal contractor. The subcontractor's occupational safety and health adviser used the results of the assessment to influence senior managers. The company procured an occupational health provider and carried out health checks and baseline health surveillance on all their workers, planning to repeat these 12 months later. The subcontractor was then re-assessed 


\section{Accepted manuscript doi: 10.1680/jcien.19.00029}

and their improvements tracked. The subcontractor was asked to share their successes and action plans with their peers. This helped promote best practice, and motivated others to work to the same standard.

\section{Hierarchy of control and designing out risk}

Hierarchy of control is the widely accepted principle (e.g. Niosh and Health and Safety Executive) that risk should be managed through the most effective methods possible, with the ideal being to eliminate hazards entirely. Methods which protect many people are preferred over methods which protect individuals. Many of the biggest reductions in health risks in recent years have been achieved through intervention at an industry level. Examples include improved tool design to reduce exposure to vibration and noise (Brereton, 2011) and removing chromate from cement to reduce the incidence of allergic dermatitis (Stocks et al., 2015). Where possible, health risks should be eliminated at the design stage. For example, on the Tideway project, designers were required to consider this. Workshops conducted by occupational hygienists provided them with information about health risks and how they arise, followed by discussions about specific areas of concern within the project and possible solutions (including examples from previous projects such as London 2012).

The outputs from the workshop were used to develop guidance for designers, including examples of high-risk activities and recommendations as to how these might be avoided or reduced. The main contractors then developed processes to ensure that risk was reviewed at every stage of the design, with challenge by 


\section{Accepted manuscript doi: 10.1680/jcien.19.00029}

Construction (Design and Management) Regulations coordinators and occupational safety and health professionals. One developed a database which acts as both a design risk register (coordinated with building information modelling) and a training tool for designers on how to minimise risk.

Several design decisions were influenced by these processes. For example

- a decision to use a precast secondary lining was shaped by the need to minimise exposure to noise and dust which could arise from in situ casting

- a tunnel-boring-machine launch frame was designed to be mostly welded off site, with final construction on site using mechanical bolting

- a new process was implemented to trim the tops of concrete diaphragm wall columns, which removed the need for on-site breaking with its attendant dust, noise and vibration.

Designing out risk at source reduces reliance on worker good practice or knowledge, unlike risk control further down the hierarchy. For example, without the use of prefabrication in the tunnel secondary lining, measures would be needed to manage dust on site. This could include the use of water suppression or extraction, which introduce costs, additional hazards and inconvenience, and masks, which would need to be of the right type and fit, and worn correctly and at all times. If such methods fail, workers are left unprotected (see Figure 9). For this reason, personal protective equipment is the control measure of last resort, only to be used if risk cannot be adequately controlled by other means. 


\section{Accepted manuscript doi: 10.1680/jcien.19.00029}

Figure 10 shows examples of interventions on Tideway at various points on the hierarchy of control.

\section{Industry standards and data management}

The research underpinning this paper identified specific challenges around occupational health services and health checks. First, there is poor understanding about the standards of health assessment which are legally required, particularly for health surveillance. Secondly, there is little to motivate employers to pay for health checks for workers who may soon move to other employers. Thirdly, the transient nature of the workforce makes it difficult to manage health data for individuals over the course of their careers, as records will be kept by many different occupational health providers.

Poor provision of occupational health services is a widespread problem in the UK, with only $14-18 \%$ of workers having access, compared to a European average of $65 \%$ and over $90 \%$ coverage in countries such as France and Poland (Fishwick et al., 2016, EC, 2017). The figure falls as low as $1-5 \%$ for those working in UK small- to medium-sized enterprises, making occupational health provision particularly problematic for construction.

For example, occupational health provision on Tideway is through a single novated supplier, to support consistency and collaboration across the project. In the early stages of the project, safety-critical medicals and other health assessments were conducted centrally by this supplier. They were generally treated as baseline assessments; there were few circumstances where health records were available 


\section{Accepted manuscript doi: 10.1680/jcien.19.00029}

which showed assessment results from previous projects or generated by other providers. This highlights the need for a process to manage health data, so that a worker who has health surveillance with multiple employers and multiple occupational health providers over the course of their career can access all the data, and occupational health professionals can use it to inform judgments.

Latterly, Tideway subcontractors have been required to put their own arrangements in place for medicals, encouraging them to take ownership of occupational health provision. However, this has the potential to fragment health data further, making it even more important that arrangements exist to 'join-up' workers' records. Such arrangements would also enable the industry to collect more accurate data on work-related ill-health to fully understand the scale of the problem.

A proposal for such a process is being developed by UK construction charity B\&CE as a replacement for the Constructing Better Health initiative. This was originally launched in 2004 by the Health and Safety Executive as a pilot programme to improve occupational health management in construction, and was acquired by B\&CE in 2016. The new model, currently in a pilot phase, recommends three-yearly health checks for all construction workers.

Health surveillance will be carried out for noise, dust, skin and hand-arm vibration syndrome where risk assessment shows these are required. Adjustments will be recommended where necessary to accommodate worker health conditions. Records will be held personally by workers through a smartphone application but will be 


\section{Accepted manuscript doi: 10.1680/jcien.19.00029}

available to occupational health providers once appropriate consents are in place.

Non-clinical health records will be available to employers.

Constructing Better Health struggled to engage successfully with very small businesses and sole traders. It was unable to persuade many of them to undertake health surveillance or seek guidance about individual workers with health conditions (Tyers et al., 2007).

Improved education of decision makers such as occupational safety and health professionals and small- to medium-sized enterprise directors is needed, to help them understand their legal obligations and also to recognise that occupational health services might bring financial benefits (Nicholson, 2017). Some construction companies are already recognising the benefits of intervention. For example, some pay for physiotherapy to help workers with musculoskeletal disorders to recover more quickly (Gibb et al., 2018): they see reduced absence, increased productivity and improved workforce retention.

\section{Conclusions}

Work-related ill health continues to challenge the construction sector despite widespread acknowledgement of its impact. Practices which eliminate or minimise health risks must be adopted throughout the sector, particularly within the small- to medium-sized enterprises which employ the majority of the workforce. To support this, interventions are needed across industry to improve training and education and to facilitate good occupational health services. 


\section{Accepted manuscript doi: 10.1680/jcien.19.00029}

Major projects are well-placed to champion such developments. For example, the Tideway project's occupational health impact scores, which are typically $90 \%$ or above (see Figure 7), suggest that a good standard of health risk management has been achieved on the project. However, comparative data from other projects will be needed to validate the scoring system.

The real impact of projects like Tideway is not just how well they manage risk themselves but how successfully they use their expertise and influence to embed change within their supply chains. Long-term improvement in the sector requires universal adoption of high standards: otherwise operators who work cheaply by putting their workforce at risk might undermine the progress of those who are trying to develop.

By supporting even the smallest operators to aspire to high standards of health risk management there is potential for these to become the new norms, as widely expected and accepted as safety boots and hard hats.

\section{Acknowledgements}

This research was funded by the Institution of Occupational Safety and Health.

\section{References}

Brereton P (2011) Impact of european directive 2002/44/ec on the risk of developing hand-arm vibration syndrome in great britain. Canadian Acoustics [online]. 39 (2), pp. 108-109. Available from:

https://jcaa.caa-aca.ca/index.php/jcaa/article/view/2381 [Accessed 13 May 2019]. 


\section{Accepted manuscript doi: 10.1680/jcien.19.00029}

British Safety Council (2018) Not just free fruit: Wellbeing at work. A literature review. [online]. Available from:

https://www.britsafe.org/campaigns-policy/not-just-free-fruit-wellbeing-at-w ork/.

Choudhry RM, Fang D and Ahmed SM (2008) Safety Management in Construction: Best Practices in Hong Kong. Journal of Professional Issues in Engineering Education and Practice [online]. 134 (1), pp. 20-32. Available from:

http://ascelibrary.org/doi/10.1061/\%28ASCE\%291052-3928\%282008\%29 134\%3A1\%2820\%29 [Accessed 28 Nov 2018].

EC (2017) COMMISSION STAFF WORKING DOCUMENT Ex-post evaluation of the European Union occupatinal safety and health Directives (REFIT evaluation) [online]. Brussels. Available from: https://eur-lex.europa.eu/legal-content/EN/TXT/PDF/?uri=CELEX:52017S C0010\&from=en [Accessed 16 Apr 2019].

Fishwick D, Sen D, Barker P, Codling A, Fox D and Naylor S (2016) Health surveillance for occupational asthma in the UK. Occupational Medicine [online]. 66 (5), pp. 365-370. Available from:

https://academic.oup.com/occmed/article-lookup/doi/10.1093/occmed/kqw 028 [Accessed 13 May 2019].

Fuller P, Gibb A, Jones W, Dainty A, Haslam R, Bust P and Pinder J (2017) Is the longbow better than the crossbow? Emerging issues from mobilising a 


\section{Accepted manuscript doi: 10.1680/jcien.19.00029}

longitudinal study on a megaproject. Journal of Construction Project Management and Innovation [online]. 7 (2), p. pp.2054-2065. Available from:

https://journals.co.za/docserver/fulltext/jcpmi_v7_n2_a6.pdf?expires=1552 491228\&id=id\&accname=guest\&checksum=31E2D60DA83CD0B00F1721 5AC495FBA1 [Accessed 13 Mar 2019].

Gibb A, Cook S, Nyateka N, Bust P, Jones W and Finneran A (2015) Wearable simulations for ill-health conditions in construction. Proceedings of the Institution of Civil Engineers. Civil Engineering. 168 (6), pp. 51-56.

Gibb A, Drake C and Jones W (2018) Costs of occupational ill-health in construction [online]. Available from:

https://www.ice.org.uk/ICEDevelopmentWebPortal/media/Documents/Disci plines and Resources/Briefing

Sheet/Costs-of-occupational-ill-health-in-constructionformattedFINAL.pdf [Accessed 21 Jan 2019].

Harrison J (2014) Planning the future: Delivering a vision of good work and health in the UK for the next 5-20 years and the professional resources to deliver it [online]. Available from:

https://www.councilforworkandhealth.org.uk/wp-content/uploads/2018/07/P lanning-the-Future-OH-and-its-Workforce-April-2014.pdf [Accessed 11 Feb 2019].

HSE (2018) Construction statistics in Great Britain [online]. [online]. Available from: 


\section{Accepted manuscript doi: 10.1680/jcien.19.00029}

http://www.hse.gov.uk/statistics/industry/construction.pdf [Accessed 3 Jan 2019].

Laitinen H, Marjamäki M and Päivärinta K (1999) The validity of the TR safety observation method on building construction. Accident Analysis \& Prevention [online]. 31 (5), pp. 463-472. Available from:

https://www.sciencedirect.com/science/article/pii/S0001457598000840 [Accessed 11 Feb 2019].

Nicholson PJ (2017) Occupational health: the value proposition [online]. London. Available from:

https://www.som.org.uk/sites/som.org.uk/files/Occupational_health_the_va lue_proposition.pdf [Accessed 13 May 2019].

Raynal A (2015) Occupational medicine is in demise. BMJ (Clinical research ed.) [online]. 351, p. h5905. Available from: http://www.ncbi.nlm.nih.gov/pubmed/26561457 [Accessed 21 Mar 2019].

Stocks SJ, Mcnamee R, Van Der Molen HF, Paris C, Urban P, Campo G, Sauni R, Jarreta BM, Valenty M, Godderis L, Miedinger D, Jacquetin P, Gravseth HM, Bonneterre V, Telle-Lamberton M, Bensefa-Colas L, Faye S, Mylle G, Wannag A, Samant Y, Pal T, Scholz-Odermatt S, Papale A, Schouteden M, Colosio C, Mattioli S and Agius R (2015) Trends in incidence of occupational asthma, contact dermatitis, noise-induced hearing loss, carpal tunnel syndrome and upper limb musculoskeletal disorders in European countries from 2000 to 2012. Occupational and Environmental 


\section{Accepted manuscript doi: 10.1680/jcien.19.00029}

Medicine [online]. 72 (4), pp. 294-303. Available from:

http://dx.doi.org/10.1136/ [Accessed 11 Jan 2019].

Tyers C and Hicks B (2012) Occupational health provision on the Olympic Park and athletes' village: Final report [online]. Available from: http://www.hse.gov.uk/research/rrpdf/rr921.pdf.

Tyers C, Sinclair A, Lucy D, Cowling M, Gordon-Dseagu V and Rick J (2007) Constructing Better Health Final Evaluation Report RR565 [online]. Available from: http://www.hse.gov.uk/research/rrpdf/rr565.pdf [Accessed 15 Jan 2019]. 


\section{Accepted manuscript doi: 10.1680/jcien.19.00029}

Figure 1. Materials handling and poor postures in construction can increase the risk of musculoskeletal disorders

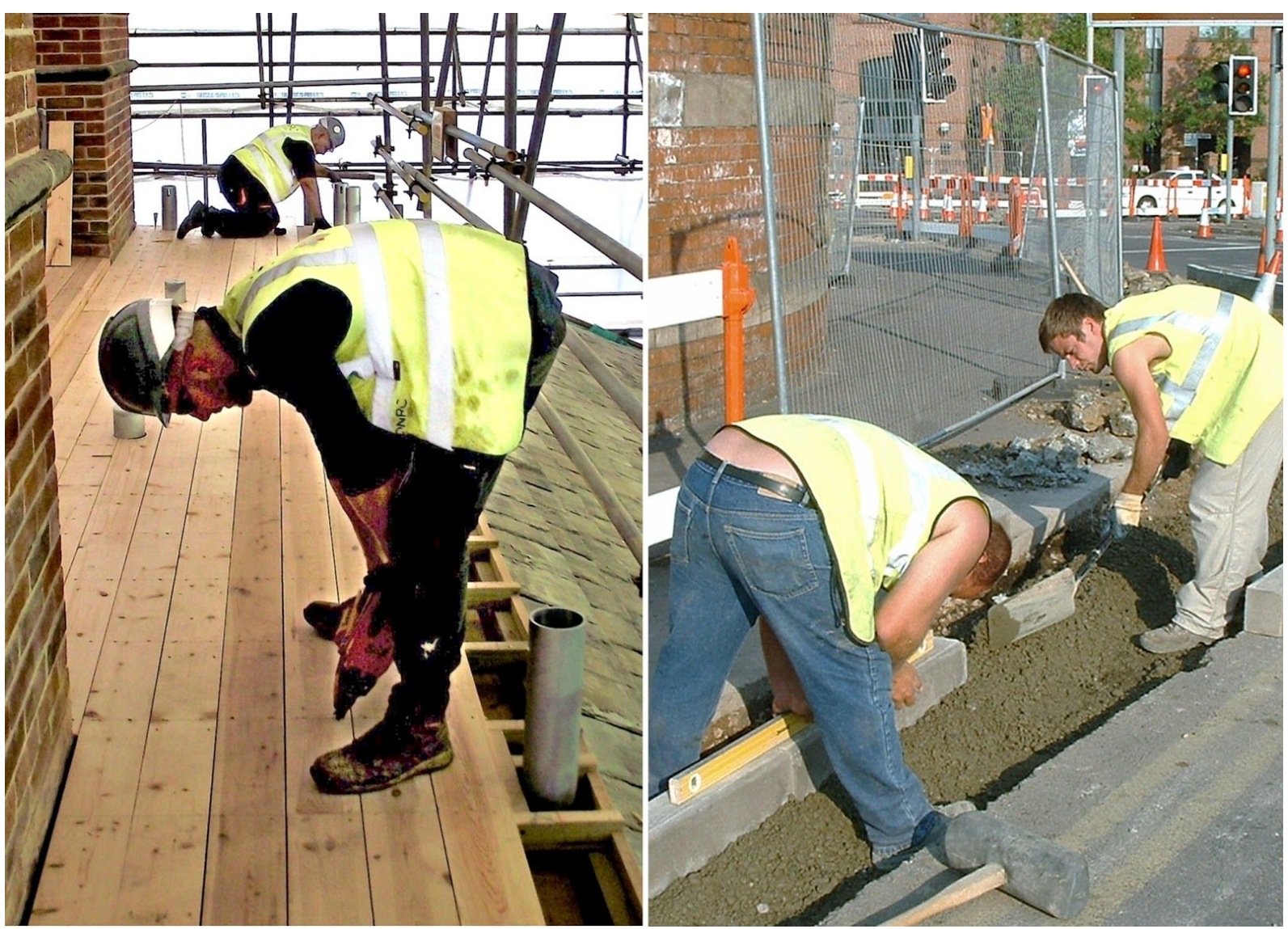




\section{Accepted manuscript doi: 10.1680/jcien.19.00029}

Figure 2. Workers may underestimate the risks from hazards such as dust and vibration or consider them to be unavoidable

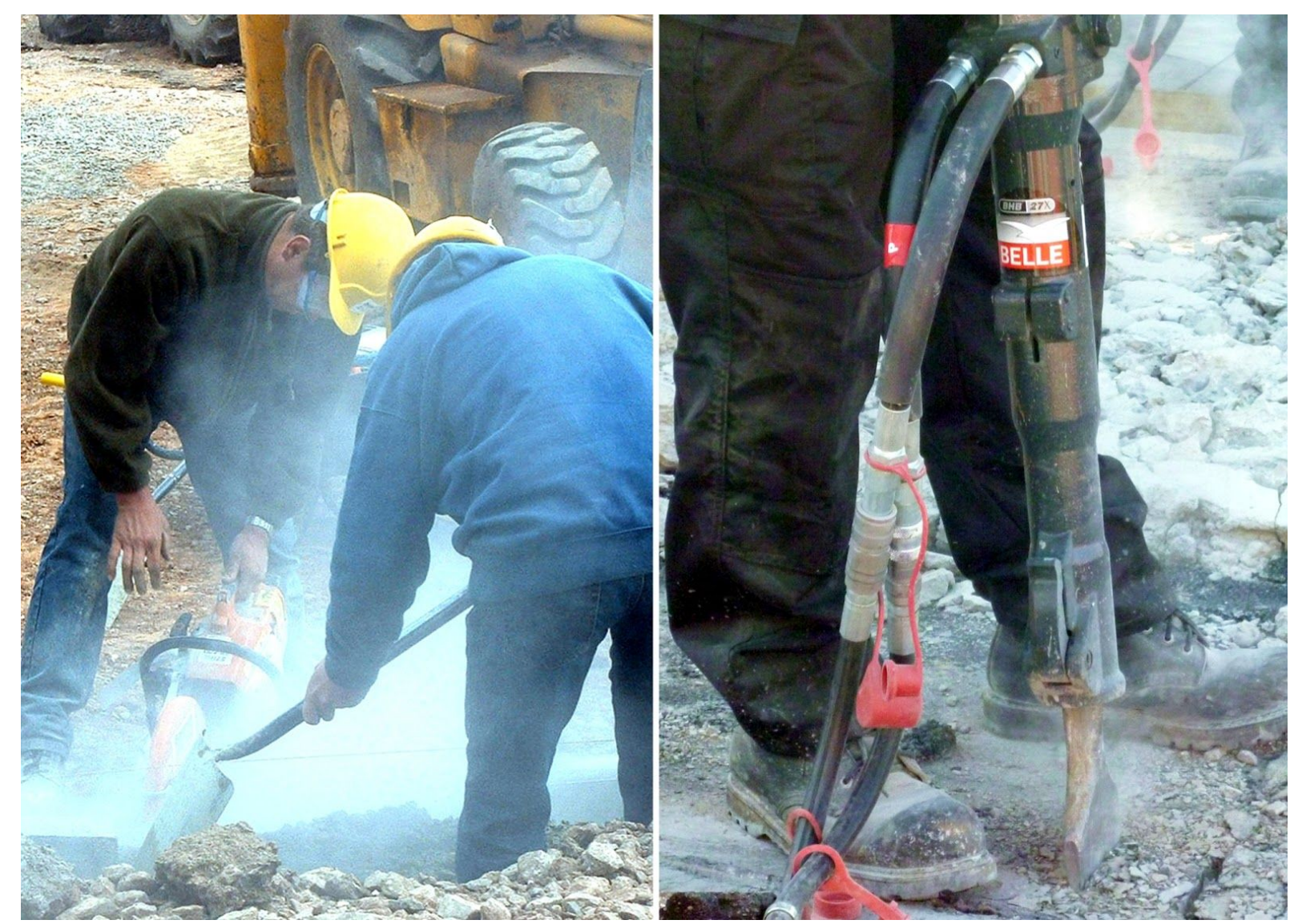




\section{Accepted manuscript doi: 10.1680/jcien.19.00029}

Figure 3. Overview of recommended measures to improve management of health risks

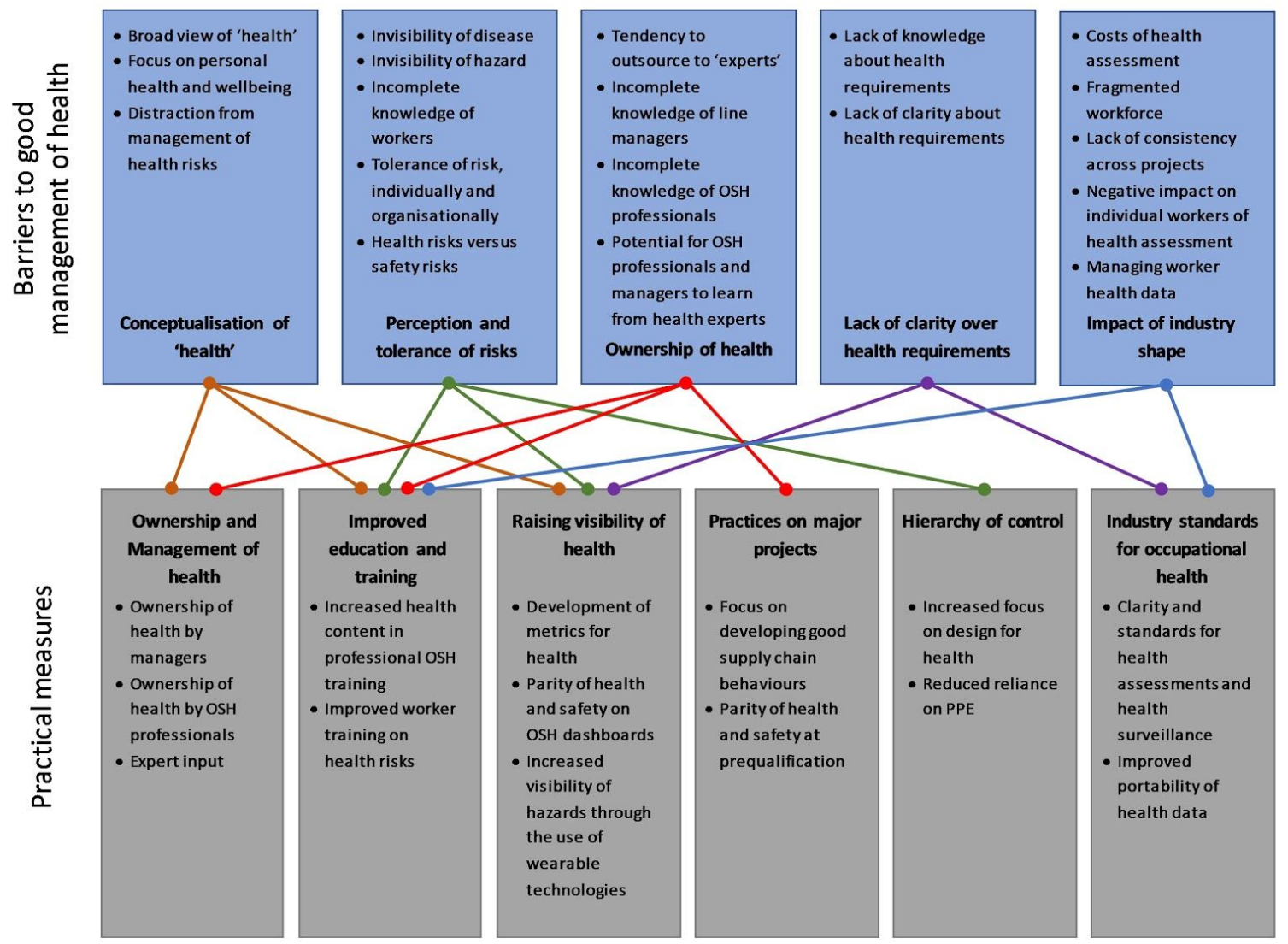




\section{Accepted manuscript doi: 10.1680/jcien.19.00029}

Figure 4. Allocation of responsibilities for different aspects of health

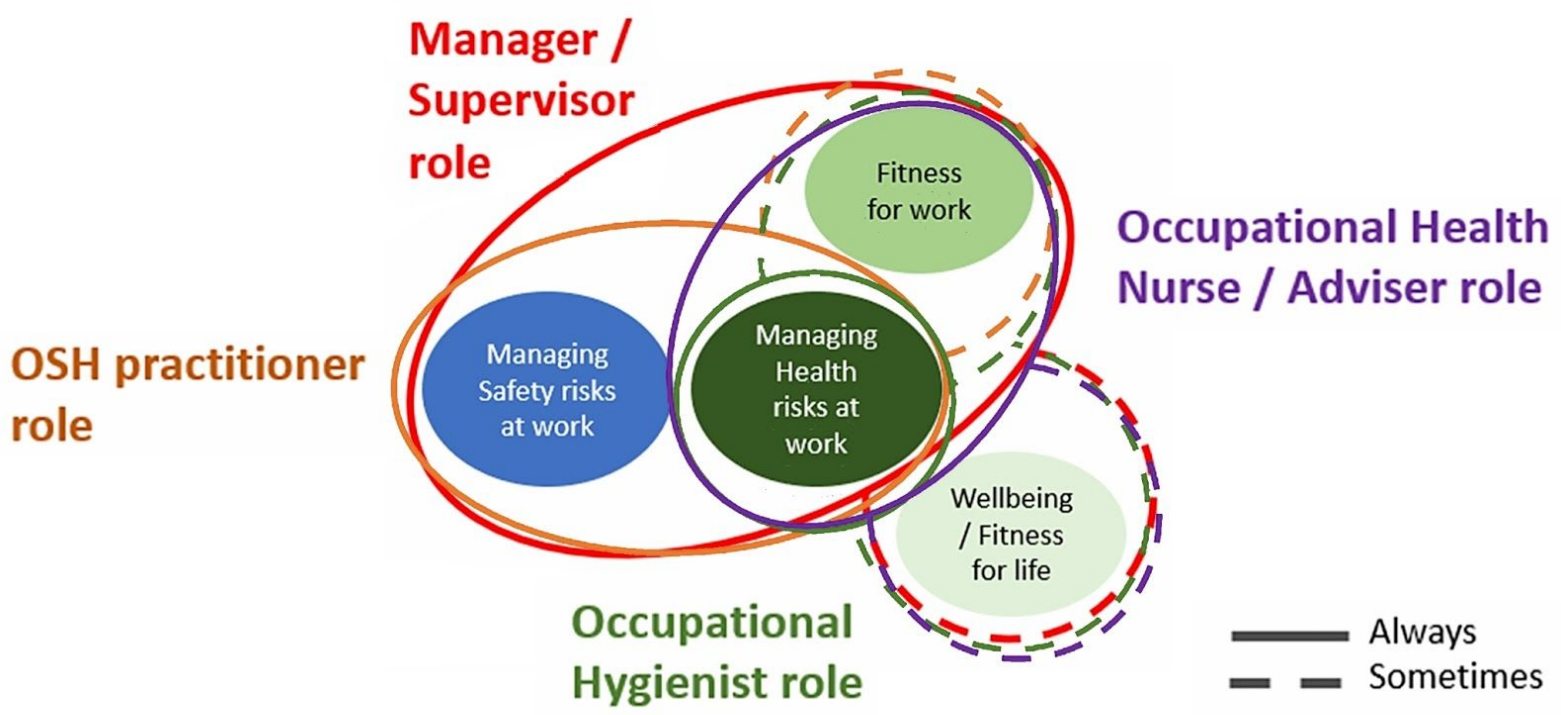




\section{Accepted manuscript doi: 10.1680/jcien.19.00029}

Figure 5. The Luskins are simulations used to help workers appreciate the impact of work-related hazards
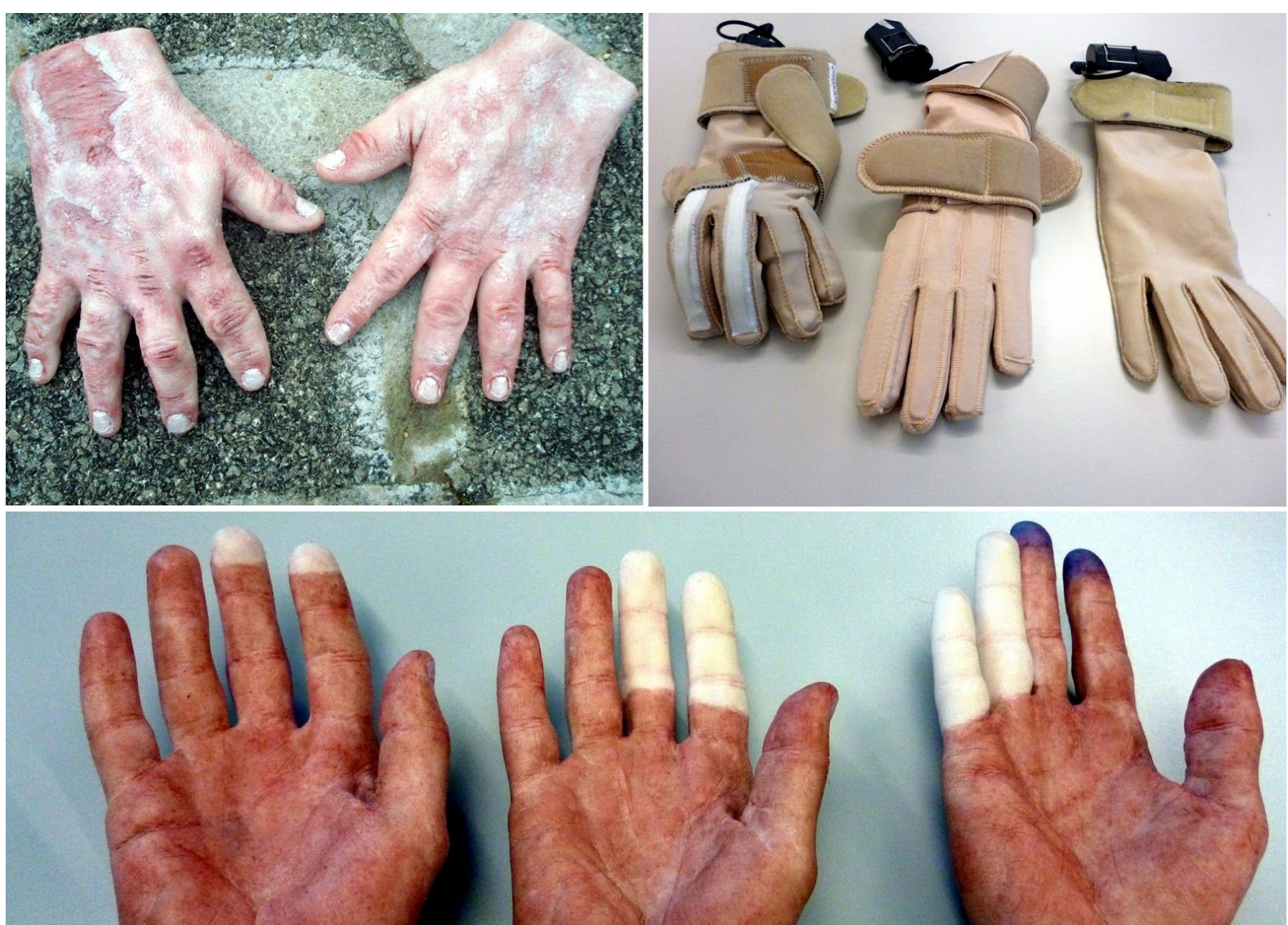


\section{Accepted manuscript doi: 10.1680/jcien.19.00029}

Figure 6. A card-based training game was developed to teach workers about typical noise levels

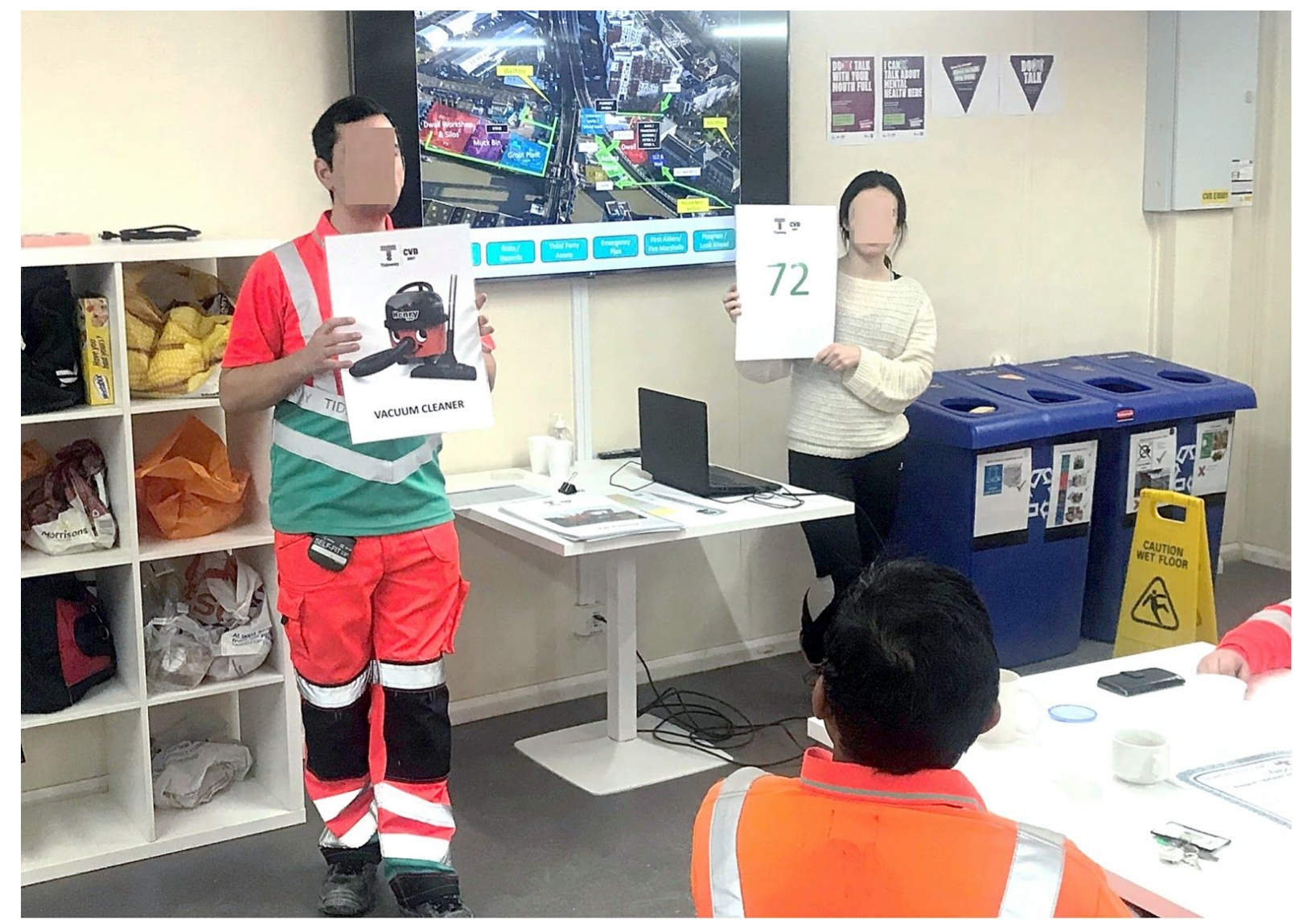




\section{Accepted manuscript doi: 10.1680/jcien.19.00029}

Figure 7. Extracts from Tideway dashboards using occupational health impact $(\mathrm{OHI})$ data: (a) the proportions of good and poor practices observed during inspections showing differences between sites, (b) scores showing variation between hazards in terms of the number of observations made and the proportion of good and poor practices and (c) trending across the project over time for specific hazards

(a) OHI Count and Scores per Site (sorted from highest score to lowest)

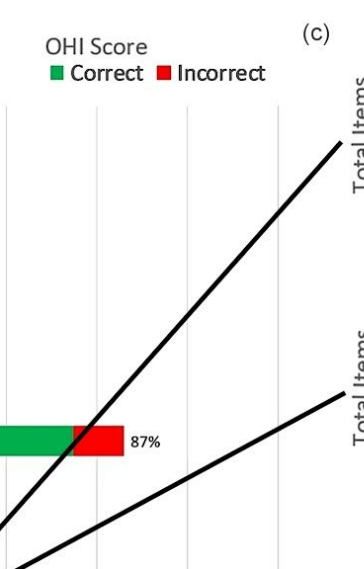

(b) OHI Count and Scores per Hazard

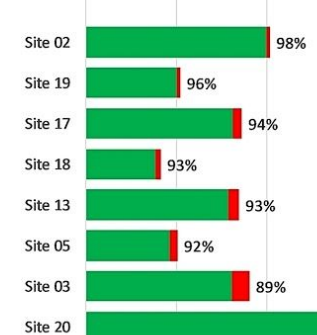

Dust Total Items $\rightarrow \mathrm{OHI}$ Score

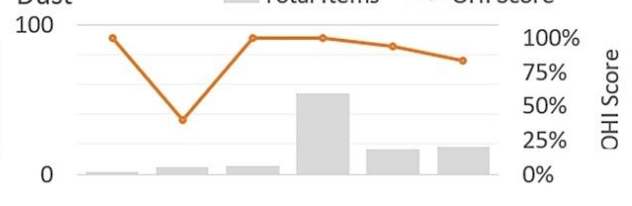

Gases Fumes

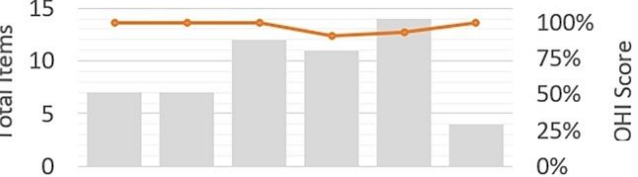

(b) OHI Count and Scores per Hazard

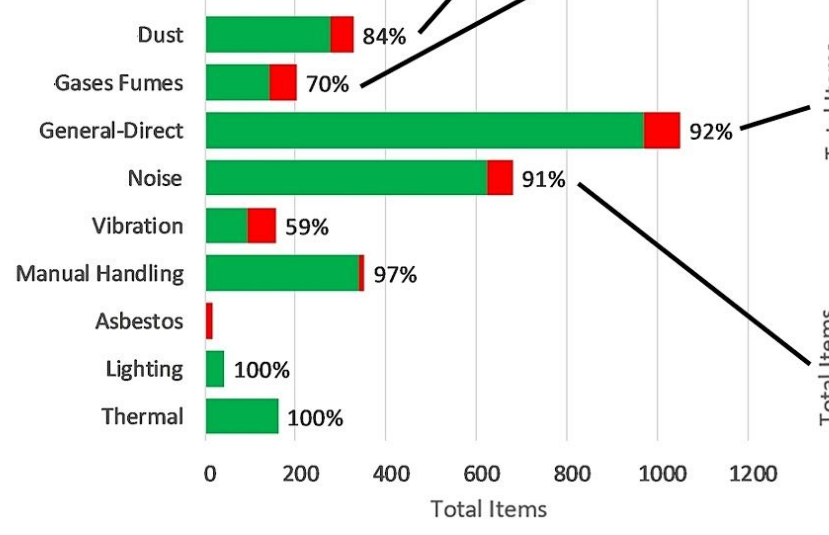

General-Direct

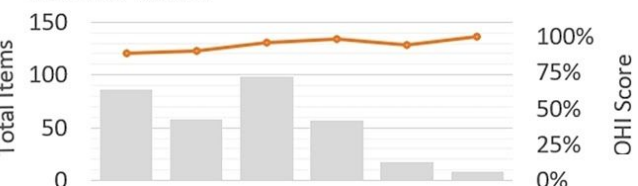




\section{Accepted manuscript doi: 10.1680/jcien.19.00029}

Figure 8. Extracts from the Tideway supply chain scheme showing the evidence

sought and how this contributes to develop an overall score: (a) detail of one of the indicators and (b) overall score

(a)

\begin{tabular}{|c|c|c|c|}
\hline \multicolumn{4}{|c|}{$\begin{array}{l}\text { Fitness for work and health surveillance } \\
\text { Processes in place to manage the health of workers }\end{array}$} \\
\hline Aims & \multicolumn{3}{|c|}{$\begin{array}{l}\text { Provides workers with access to occupational health services. } \\
\text { Has adequate programme to ensure workers' health is managed in } \\
\text { accordance with their job role. } \\
\text { Adequate support in place when ill-health arises. } \\
\text { Meets legal requirements for health surveillance to ensure workers health isn't } \\
\text { affected by their work and proactive approach to managing the outcomes of } \\
\text { the programme. }\end{array}$} \\
\hline \multicolumn{2}{|l|}{ Question } & Evidence & Score \\
\hline \multicolumn{2}{|c|}{ Is there a fitness for work programme in place? } & & $0-3$ \\
\hline \multicolumn{2}{|c|}{ Is there a process in place to manage the ill-health of workers? } & & $0-3$ \\
\hline \multicolumn{2}{|c|}{ Is there a policy and procedures for managing drug and alcohol misuse? } & & $0-3$ \\
\hline \multicolumn{2}{|c|}{ Is there a health surveillance programme in place? } & & $0-3$ \\
\hline \multicolumn{2}{|c|}{ Do outcomes of the programme inform proactive health initiatives? } & & $0-3$ \\
\hline & & & Total \\
\hline $\begin{array}{l}\text { Other evidence of best } \\
\text { practice: }\end{array}$ & \multicolumn{2}{|c|}{$\begin{array}{l}0 \text { No } \\
1 \text { Yes, but limited evidence / implementation } \\
2 \text { Yes, good evidence and expectation generally met } \\
3 \text { Yes, expectation met and examples of best practice }\end{array}$} & $0-15$ \\
\hline
\end{tabular}

(b)

\begin{tabular}{|c|c|c|c|}
\hline Company: & \multicolumn{3}{|c|}{ (Sub-contractor) } \\
\hline Project: & \multicolumn{3}{|c|}{ (Main contractor; section of Tideway) } \\
\hline Undertaken by: & \multicolumn{3}{|c|}{$\begin{array}{l}\text { OSH professional for Main Contractor } \\
\text { OSH professional for Sub-contractor }\end{array}$} \\
\hline Leading indicator & \multicolumn{3}{|l|}{ Score } \\
\hline Strategy and leadership & 11 & $73.3 \%$ & \multirow{4}{*}{ Silver } \\
\hline Risk assessment and control & 12 & $80.0 \%$ & \\
\hline Fitness for work and health surveillance & 13 & $86.7 \%$ & \\
\hline Wellbeing & 8 & $66.7 \%$ & \\
\hline
\end{tabular}




\section{Accepted manuscript doi: 10.1680/jcien.19.00029}

Figure 9. Engineering and administrative controls and person protective equipment rely on workers knowing when and how to use them: this worker has a poorly fitted face mask, and is using a broom to sweep up dust despite a vacuum being available

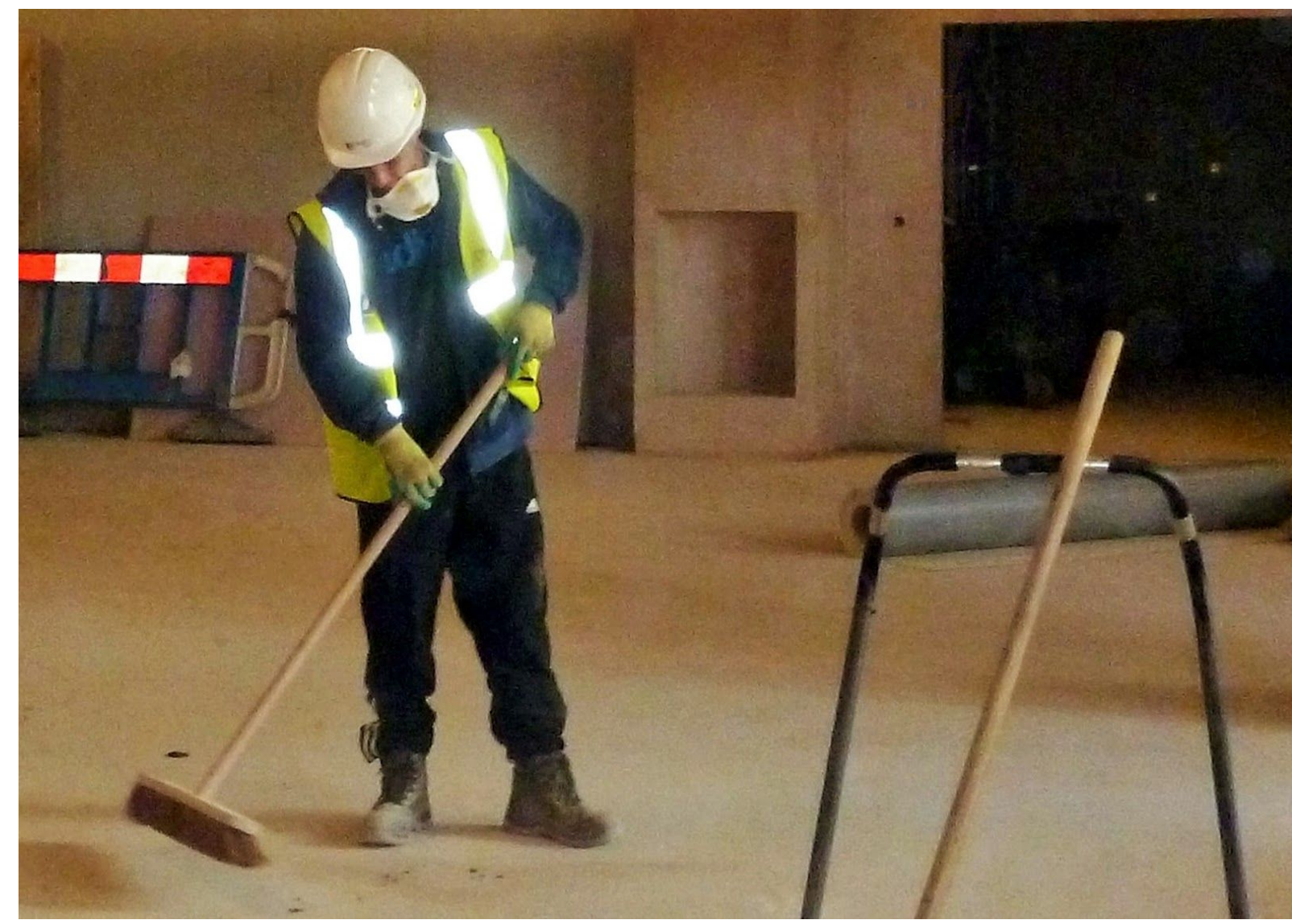




\section{Accepted manuscript doi: 10.1680/jcien.19.00029}

Figure 10. Hierarchy of control with examples of how Tideway have managed risk

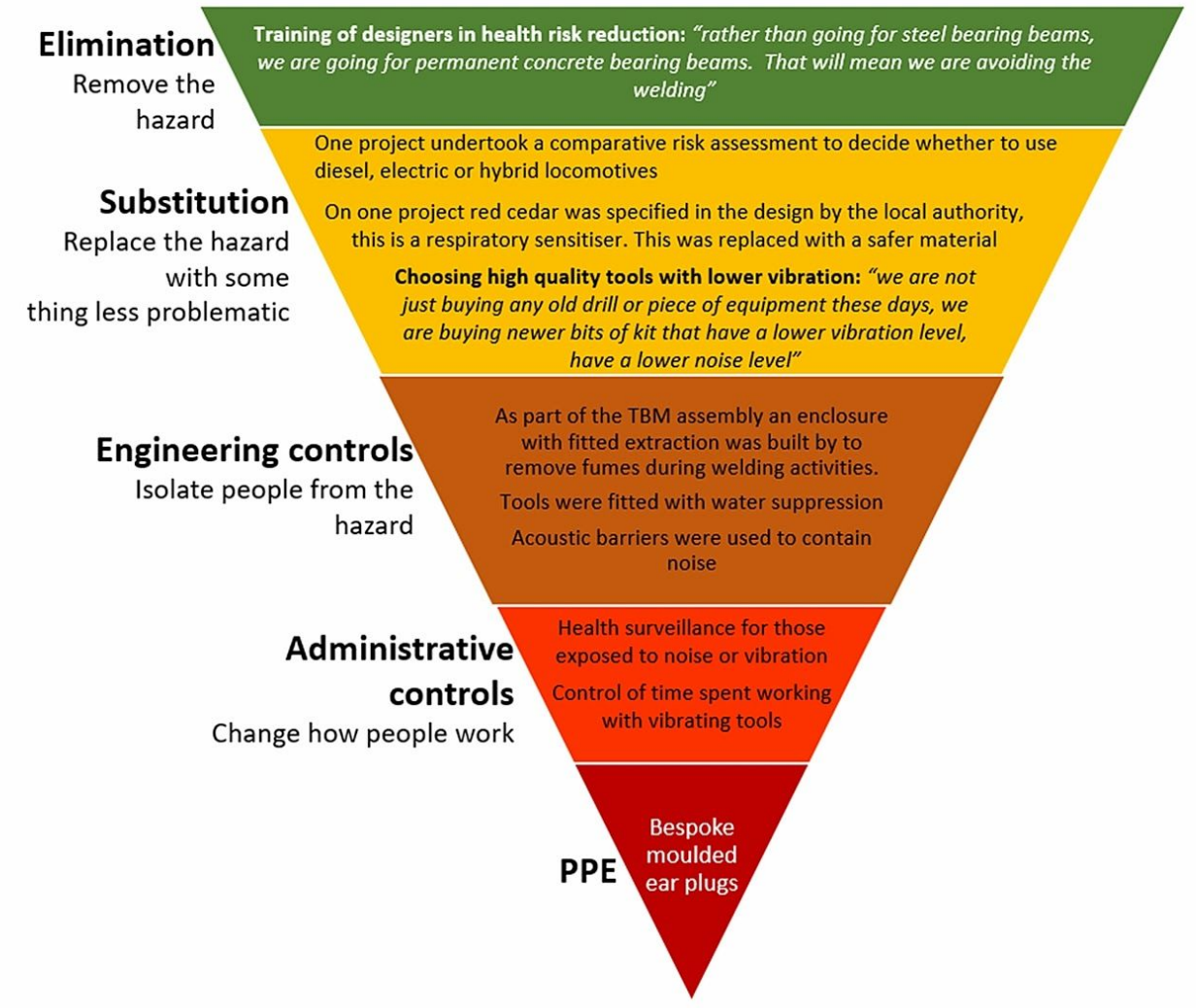

